\title{
Range Management Training in Developing African Nations
}

\author{
ARTHUR D. SMITH AND DON D. DWYER
}

\begin{abstract}
Assistance programs in range management to developing countries in Africa by the U.S. Agency for International Development historically have had a training program for nationals for the host countries as part of the package. These have been extremely valuable and, in the long run, are likely to provide the major benefits to recipient nations. They could become even more effective if closer coordination between U.S. universities, host government officials, and USAID personnel were achieved. This would result in more varied educational programs tailored to suit the needs of each student trainee and each host country, thus saving time and money.
\end{abstract}

Aid to developing countries by the U.S. Agency for International Development (USAID) in the field of range management has typically comprised three kinds: capital investments in structures, technical aid rendered by expatriates in selected government positions in the host country, and training programs for upgrading the skills of host country nationals.

The first of these involves such things as water development (wells, boreholes, and ponds), road building, and animal handling facilities such as corrals and dipping vats. These are all proper and useful devices for increasing animal production from rangelands, but if developed without well-designed management plans they are fraught with perils. The availability of sophisticated mechanical equipment for installing such aid and the fact that results are immediately and highly visible tend to cause those responsible to point to the numbers of structural installations as a main measure of success. Their long-time utility and contribution to range betterment is another matter. Unless government officials, as well as pastoralists, understand range ecology (and this is usually rare) range developments of the sort enumerated may actually lead to reduced production and range deterioration. Based on past experience in the United States and abroad, considerable ecological degradation can result from too hasty and ill-planned developments, and the same may be true even for well-planned ones where range management principles and concepts are not widely understood.

Technical assistance by means of supplying range-trained personnel, though a necessary and vital ingredient of a rangeland development package, has not been without its problems. The number of positions provided by past levels of funding for USAID account for a small number of individuals spotted here and there throughout the host government structure. A large share of the in-country problems can often be traced to insufficient awareness and knowledge of the local culture by USAID supplied personnel. Cultural differences between expatriates and nationals can give rise to tensions and jealousies which limit the effectiveness of technical personnel that are provided. And of even more importance, the lack of ecological sophistication of the pastoralists, together with their deeply ingrained customs, make the transfer of technology a slow and tedious process. This transfer of technological knowledge cannot be accomplished without an increasingly large and competent cadre of nationals who have scientific and managerial training in the philosophy and skills of range management. Thus, it appears to us that in the long run, effective educa-

\footnotetext{
Authors are Professor Emeritus, Range Management, and Professor and Head, Department of Range Science, Utah State University, Logan 84322.

Manuscript received July 12, 1979.
}

tional programs will be important in determining the success of rangeland development projects in Lesser Developed Countries (LDC).

We feel the training component of foreign assistance programs should be strengthened and give more critical attention in the future than appears to have prevailed in the past. Based upon our experience, selection of trainee candidates has not always been pursued aggressively and analytically and, in consequence, the scope and effectiveness of training programs have suffered.

Traditionally, AID training programs have included (1) shortterm extension programs directed to such lay persons as herdsmen and pastoralists in the host country; (2) short-term nondegree technological courses abroad; (3) undergraduate instruction in professional colleges and universities abroad, usually leading to a baccalaureate degree; and (4) advanced study toward the MS or $\mathrm{PhD}$ in universities abroad. The last two of these are our special concern.

\section{Level of Training}

In most developing countries, the BS degree provides an adequate scientific foundation for staffing a range management organization and developing a rangeland management program. The additional scientific knowledge represented in graduate programs is not necessary for most of the people entering such organizations. The level of education among native herdsmen is such that highly sophisticated techniques cannot be applied by them at the outset. This does not mean that graduate level training is not appropriate, but that meeting the present capabilities of developing countries to apply range management technology requires far fewer graduate than undergraduate degrees.

For most developing countries MS programs could provide the necessary background for staffing upper-level administrative positions in government agencies and for engaging in adaptive research. The additional years of education beyond the BS would allow recipients the greater prestige necessary to deal with officials in the ministerial hierarchy, who are often political appointees. In addition, the opportunity to broaden the knowledge and experience of the individual receiving graduate instruction is valuable.

Very few developing countries have great need for degree holders at the doctoral level. In cases where research in range management is in progress, or where it is being developed, $\mathrm{PhD}$ holders may be required. Certainly, if BS level educational programs were to be developed at universities and colleges in developing countries, there would be additional need for training to the PhD level to fill some faculty positions (Dwyer and Box 1978). Many such positions could be staffed by MS degree holders, for the present at least, whether in research or teaching capacities. After all, the level of sophistication of range management for some time to come will be far below that presently attained in the United States, and even here the last of the faculty and research personnel who have creditably held productive positions without doctorates are just now phasing out. The argument is not against higher level training, rather it is to suggest that with limited funds, time, and in some cases, available candidates, faster progress can be made by speading the educational effort among more individuals and gearing training to needs of the country. 
Although we are convinced of the rationality of this approach, we recognize there are difficulties. Unfortunately, historical precedent in most developing nations places great incentive for the individual purusing education abroad to obtain the doctorate as a matter of prestige. In countries where progress has been greatest, a large number of government officials in ministries of agriculture hold $\mathrm{PhDs}$ whether they are expatriates remaining from colonial governments or whether they are nationals. They may also be practical stimuli as well as civil service rules and regulations which govern salaries, promotion, and advancement. So long as these pressures remain, it may be difficult to adhere to the course we outline here, for it may satisfy the needs neither of the individual nor the government. We feel strongly, however, that the United States has been guilty of over-educating third world personnel and prolonging the educational experience much beyond the need. Where this happens, not only is the home country deprived of the service of the trainee, but long absence from home often lowers the effectiveness of the individual pursuing the advanced degree. Few of the posts where service is required offer the advantage of life as it is in the United States, and this can lead to a reluctance on the part of the trainee to return home and deal with the nitty-gritty of life there. Thus, many individuals obtaining the $\mathrm{PhD}$ are lost to their home country when they choose to work elsewhere.

\section{Location of Training}

To the present, training for academic degress in range management has been conducted in the United States. Short-term extension training among junior technicians is usually done in the home country.

There are persuasive philosophical arguments for expanding training programs in the host countries of those working toward academic degrees. Costs would probably be reduced and more people could be brought into the program. There are practical disadvantages involved, however. Few U.S.-trained range managers qualified to instruct in undergraduate programs have the language capability to perform effectively in French-speaking West Africa. This is particularly unfortunate because of the extensive rangelands there and the critical ecological problems they present. Even in former British colonies of East Africa where English is widely spoken, linguistic barriers exist. Dealing with government officials may pose no problem, but contact with lay persons does.

A further obstacle to mounting university level programs in the developing countries is that with few exceptions there are neither facilities to house such programs, nor adequate supporting coursework in academic disciplines related to range management. There are exceptions. In Kenya and in Sudan existing universities could cope with both these obstacles. So far, despite considerable attention, efforts to develop a range management curriculum and instruction at the University of Nairobi have not been fruitful. There are plans underway to upgrade and expand the range management curriculum at Egerton College where the 3-year diploma thus far has been the most advanced work in range management obtainable in Kenya (Dwyer and Box 1978).

Most of the African countries, excluding southern Africa, do not have the facilities for undertaking teaching at the baccalaureate level. Many existing schools of agriculture in the least developed arid countries lack the competency to provide university education at the upper collegiate levels. For most, the junior college or a lower division instruction is all that is available. Introductory courses may be offered but the general preparational level of students is inadequate background for more advanced training, and support in related scientific fields is lacking.

Because of these difficulties, for some time at least, the present practice of bringing third world nationals to the United States for degree training will continue to be the dominant pattern. This offers the trainee possibilities for contact with many individuals in range management as well as those in related fields. The breadth of such contacts in the United States is much greater than would be possible in the third world.

There is a further consideration offering advantages that needs emphasis. Throughout much of Africa there are national barriers to cooperation and free exchange between nations. Even within individual countries, tribal differences lead to frictions, distrust and, in many cases, to local armed encounters. Our experience causes us to believe that many regional and tribal differences have their roots in general lack of understanding among Africans or African history and cultures. An effort should be made to correct this. Not all, but some universities have departments of African studies, or at least have staff members offering courses in the field. Where these capabilities exist, African nationals should be required to include such classes in their course schedules.

\section{Emphasis on Degree Program}

Foreign nationals trained in the United States have been subjected to curricula developed for U.S. students and U.S. conditions, perhaps with minor exceptions. Undergraduate instruction provides the basic scientific background in supporting fields and in the principles of range management. Advanced degrees both at the $\mathrm{MS}$ and $\mathrm{PhD}$ level are, in the main, research oriented.

We believe that research-oriented degrees rarely are best suited to the requirements of most developing countries. The present and short-run need is trained personnel for government positions in agriculture and natural resources ministeries. Now, these are likely to be occupied by expatriates remaining from colonial times or by nationals who have been trained in other countries. Few of these people have received training in range science. Most commonly their backgrounds are in animal production, veterinary medicine, or ecology. Since this training, in ecology especially, is likely to have been received in Europe, where environmental conditions contrast drastically, their education does not prepare them to deal adequately with arid environments and cultures characteristic of African rangelands. Economy of time and money would be best served if these administrative positions were filled with MS degree holders. The degrees should be oriented to administration and personnel management, rather than to research. Time spent emphasizing statistics and data gathering, analysis, and interpretation could probably better be devoted to obtaining insights into public administration and cultural anthropology. Special written reports would substitute for the thesis, an opportunity provided in some institutions by a Plan B thesis option. Properly administered, this option is quite as rigorous as the research-oriented plan, yet provides opportunity for a broader field of training and greater flexibility.

$\mathrm{PhD}$ level training should, in our view, be provided only where a research capability exists in the country in question, is in the process of being implemented, or where staffing at a university is contemplated. A limited number of developing countries would qualify under these criteria.

\section{Location of Trainee Research}

Research philosophy and methods can be effectively provided outside the host country, but it is not possible to duplicate conditions there, thus limiting the transferability of any information developed. Responses of a sagebrush range to treatments in the Great Basin would have little relevance for East Africa. There seem to be valid reasons for perfecting arrangements which would permit a PhD candidate (it is doubtful that any attempt should be made to follow such a course for MS training) to conduct research in his home country. If this were done, the research findings would be applicable to that region and the research methodology would be no less useful as a training medium. There are, however, certain drawbacks to be overcome.

To make such a procedure function effectively, it is imperative that the major professor visit the home country to become familiar with the conditions there and assess the research plan in relation to these conditions. Otherwise, the student's advisor would be in no position to judge the quality of the research effort. In addition, it would provide an opportunity for establishing liaison with officials in the host country and promoting support for the candidates' 
efforts. This is critical. Based on limited experience, we have so far seen little progress in the way of accomplishment once a student returns home with plans to complete the dissertation research there. We think that if concerned officials in the developing nation and the students' major professor were in contact with each other, relevant research programs in which the government had an interest could be worked out. Greater support should, therefore, be expected.

The plan, as we see it, would work something like this: qualified candidates working in certain aspects of an AID project would be carefully selected for advanced training at a U.S. university. The student would complete basic coursework requirements and outline a proposed research program; he would then return to his home country; the major professor would immediately visit the student there and develop on location the details of the research to be conducted. After the research results are in hand, the student would return to the United States to complete writing a dissertation and other formalities.

This plan might be more expensive than the one now being followed, but this is unproven. There would be additional travel of the student, and time involved in the degree program would probably be increased. There would be additional costs of travel by the major professor. Advantages which would offset these extra costs are: the time spent in research could be made productive both to the AID project supporting the trainee and the host country; the research itself would be more meaningful to the student and to the country; less expense would be incurred to support research in the home country than abroad; and a mutual confidence would be established between the host country and the training institution. The long-run benefits might be even greater. The fact that there would be an ever-widening pool of U.S. educators familiar with conditions in developing countries should improve the character of training for other students, both foreign and U.S. who come in contact with U.S. faculties. Range management principles would be better presented to third world nationals if professors understand the conditions under which they must be applied.

\section{Availability of Trainee Candidates}

One handicap to wide application of range management training is found in the comparatively low average level of education in many developing countries. This is reflected in a dearth of candidates having sufficient education to qualify for work at a college or university. In Botswana in 1976, for example, USAID training quotas went unfilled for this reason (Smith et al. 1976). Even getting acceptance at middle-level institutions in Africa (Egerton and AHITI in Kenya for instance) was not fruitful, although factors other than academic standing may also have been at play. Similar problems may exist among certain tribal cultures within the more favored and advanced countries. Nomadic tribes are likely to have fewer opportunities for schooling than sedentary tribes. Because of their shifting about in search of water and pasturage, schools cannot be established among them. Inadequate representation from each cultural group may be the consequence of these factors.

This can be solved to some extent by bringing students to centers where boarding schools can be established. The village settlement program pursued among the Masai in Tanzania was an effort to improve educational opportunities for them. But obstacles to increasing schooling among pastoralists lie in the reluctance of tribal elders to let the youth become separated from the family and tribal influence, since it interferes with traditional ceremonial and ritual observances expected of each member of the clan.

These obstacles are only inconveniences to be overcome; means must be found in training programs to reach all tribal and ethnic groups, for it is among these less advanced elements that the dependence upon a stable rangeland resource is most critical. Unless the Somalis, the Nilo-Hamitic tribesmen of East Africa, the Baggara of Sudan, and the Fulanis of West Africa can be made aware of the consequence of improper use of their rangelands there can be no solution to range degradation and desertification in those countries.

Some argue that pastoral cultures have developed ecologically balanced systems. But this condition, if it existed, depended upon periodic catastrophe to maintain an equilibrium at great cost in life among animals and humans. These solutions are no longer tolerable. Moreover, the system has already been altered. Widespread dissemination of drugs for disease control among livestock has reduced this constraint on herd numbers; and, without it, domestic animal populations quickly outgrow the limits of the forage base. Similar factors are operative among human populations. The consequence of these disturbances is that the potential pressure upon rangeland resources is much greater than in the past. If we are unwilling to rely on nature's way of maintaining a balance among man, animals, and forage, and it seems evident that we are unwilling to accept this uncompassionate method, then we must design management systems that will maintain a balance. The most effective means for doing this is through education.

The educational component of USAID has not been used effectively enough in view of its important role in contributing to range management programs of developing nations. The international education programs which have been supported have been endorsed with a perspective of too short a term and with too little vision. and U.S. institutions have given their consent to them through passive acceptance rather than challenging them. To implement land use plans based on ecology requires knowledge gained through education, and any educational program must be viewed seriously and over the long term.

We recommend that educational programs in USAID become at least as important in range management aid to LDC's as programs which implement action projects. They must also seek to enhance capabilities of U.S. institutions to provide more relevant range management education for LDC nationals as well as to support the foreign students throughout their education. This is in keeping with the intent of Title XII legislation which supports the concept of planning programs over at least a 10--year period.

\section{Literature Cited}

Dwyer, Don D., and Thadis W. Box. 1978. Range management curriculum review and development at AHITI, Egerton College, and University of Nairobi. USAID Project No. AID/afr-C-1140, Utah State University. Mimeo. $73 \mathrm{p}$.

Smith, Arthur D., Derrick J. Thom, and Gary C. Bond. 1976. Evaluation of the Botswania range management and development. USAID Project No. 690-11-130-015, Part I. Consortium for International Development. mimeo. $58 \mathrm{p}$. 